\title{
Drug Repurposing in the Treatment of COVID-19
}

\section{COViD-19 Tedavisinde ilaç Yeniden Konumlandırma}

\author{
(i) Mehmet SOYLU, iD Emine Nur ÖZBEK, iD Günay YETIK ANACAK
}

Ege University Faculty of Pharmacy, Department of Pharmacology, İzmir, Turkey

\begin{abstract}
The use of drugs that have been previously defined for certain indications in new indications is defined as the repurposing/ repositioning of the drug. The requirement of all clinical research steps that starts from healthy volunteers, due to the slowness of new drug discovery, longer time to reach the market, and high cost to develop a new drug, make drug repurposing an attractive pharmacoeconomic solution. Repositioning of drugs becomes even more important, especially in situations where time is vital and emergency in drug development such as pandemics. In this review, we have both summarized the techniques used for drug repositioning and evaluated drugs that have been repositioned in Coronavirus Disease (COVID-19) treatment based on three main strategies, target-disease and drug-based. Considering the availability of the results of pharmacovigilance studies and long-term toxic effects of old drugs provide an important advantage compared to traditional drug discovery in COVID-19 treatment, where sepsis and multiorgan dysfunction can occur.
\end{abstract}

Keywords: COVID-19, drug repositioning, computer-based approaches

\section{ÖZ}

Daha önce belirli endikasyonlar için tanımlanmış olan ilaçların yeni endikasyonlarda kullanımları ilacın yeniden amaçlandııılması/ yeniden konumlandırılması olarak tanımlanmaktadır. Yeni ilaç geliştirmek için gereken sağlıklı gönüllülerden başlayan tüm klinik araştırma adımları, bunlara bağlı ilaç keşfinin yavaş ve ilacın piyasaya ulaşma süresinin uzun olması ve dolayısıyla da yüksek maliyet nedeniyle, yeni ilaç keşfi yerine eski ilaçların yeniden konumlandırılması farmakoekonomik bir çözüm olarak ortaya çıkmaktadır. Özellikle zamanın hayati önem taşıdığı ve acil ilaç geliştirilmesi gereken pandemi gibi durumlarda ilaçların yeniden değerlendirilmesi daha da önem kazanmaktadır. Bu derlemede hem ilacın yeniden konumlandırılması için kullanılan teknikleri özetledik, hem de hedef hastalık ve ilaç temelli olmak üzere 3 ana stratejiye bağlı olarak Koronavirüs Hastalığı-19 (COVID-19) tedavisinde yeniden konumlandırılan ilaçları değerlendirdik. Eski ilaçların farmakovijilans çalışmalarının sonuçları ve uzun vadedeki toksik etkiler dahil görülebilecek yan etkilerin bilinmesi nedeniyle sepsis ve çoklu organ yetmezliğine gidebilen COVID-19 enfeksiyonunun tedavisinde kullanılacak ilaçların keşfinde ilaçların yeniden konumlandırılması yöntemi geleneksel ilaç keşfine kıyasla önemli bir üstünlük olarak ortaya çıkmaktadır

Anahtar Sözcükler: COVID-19, ilaç yeniden konumlandırma, bilgisayar temelli yaklaşımlar

\section{Introduction}

Pneumonia cases of unknown cause were started to be reported in China on December 31, 2019. A new coronavirus (CoV) severe acute respiratory syndrome CoV-2 (SARS-CoV-2) was identified as the cause of these cases on January 7,2020. Due to the spread of the virus worldwide, it was declared a global epidemic by the World Health Organization on March 11, 2020. The SARS$\mathrm{CoV}-2$ virus, which is estimated to be transmitted to humans from the seafood and "wet" animal market in Wuhan city, has stick-like protrusions on its surface. CoV, the enveloped RNA virus, whose name is also given based on these protrusions, are single-stranded 
and positive polarity (1). CoV cause a wide variety of clinical pictures in humans, ranging from the common cold to SARS, and in severe cases, kidney failure or even death. Considering the high mortality rates caused by SARS-CoV-2 and the spread rate of the virus, it is important to develop drugs against this disease quickly.

Development of a drug depends on successful steps following the identification of the target, including literature research for the precursor compound, preclinical studies, phase (I-II-III) studies, approval, and phase IV studies. This process takes a long period of about 15-20 years. Moreover, due to the failures that can be seen in the phase studies of the drug molecule, the efficiency of drug development in the traditional method is low. In order to reduce the cost of synthesis and screening of drug molecules and to shorten the duration, it is necessary to resort to the drug repositioning method, which is defined as the use of available licensed drugs in drug design and development for new therapeutic purposes (2). This method, known as drug repositioning, drug repurposing, drug rescuing, therapeutic switching, drug reprofiling, drug indication expansion, drug indication shift, and drug retasking, is a strategy for defining a new indication to an existing drug or drug molecules under study other than the original medical indication. Acetylsalicylic acid, thalidomide, sildenafil, and minoxidil are the best known examples of repositioned drugs from past to present (3).

Since the efficacy, safety, toxicity, and clinical effect information of the approved drugs are already available, their safety has been tested in early studies, and their pharmacology and formulations are known, the introduction of these drugs in a new indication within the scope of repositioning is rapid. One of its most important advantages is the low failure risk. Also, the ability to reduce the required clinical trial steps reduces the time and cost of the drug to reach the market. Due to these advantages, the drug repositioning strategy is one of the most powerful methods in developing drugs for the treatment of diseases such as COVID-19, which is considered as a global epidemic that causes the death of many people by spreading rapidly and affects the whole world negatively. However, despite all its advantages, drug repositioning has some difficulties. First, the dose required to treat the new disease may differ from the disease in the original indication, and in this case, omission of phase I clinical trials, one of its advantages against de novo drug development, is not possible. Second, when new formulations and new distribution mechanisms of existing drugs are in question in new and specific diseases, seldom it is required to perform pharmaceutical and toxicological studies again. Third, patent rights issues can become much more complex due to the lack of legal expertise in drug repositioning (4).

\section{Techniques Used in Drug Repositioning}

\section{Chemical Structure-based Methods}

Molecular docking is a target-based approach that allows us to model the behavior of two interacting molecules (protein/ ligand, protein/protein) at the atomic level and elucidate the basic bonding mechanisms. This approach uses 3D models of the target and candidate ligand. The basic steps of the molecular docking process are: 1 - Creating the 3D structure of the target and ligands, 2- Placing the ligand in the target's binding site, and 3- Calculating the binding affinity. The last step is to score how strong the interaction between the target and the ligand is (5). Various computer softwares are available to perform these basic steps.

In molecular docking studies, virtual screening of large structural libraries containing chemical formulas of existing drugs and/ or drug candidate compounds is performed, and interactions between a molecular target of interest and candidate compounds are evaluated. Virtual scanning provides time and cost advantages; because it eliminates the need to purchase hundreds of compounds to synthesize new molecules. The combination of virtual scanning and drug repositioning methods gives promising results in drug development studies. For example, by scanning protein databases, the antiparasitic drug mebendazole was also shown to be a vascular endothelial growth factor receptor 2 inhibitor by the molecular coupling method (6). Although molecular docking is a very popular and widely used approach, it also has several limitations. The 3D structure of the target must be present before molecular coupling can be used. In the absence of this data, homology modeling can be performed for the target, but in this case, the obtained structure of the target may not be exactly the same as the reality. In addition, molecular docking studies can become inefficient due to lengthy calculations in large-scale analyzes (7).

\section{Ligand-based Methods}

Ligand-based methods include pharmacophore modeling, quantitative structure-activity relationship (QSAR), and reverse docking methods. These approaches are based on the idea that structurally similar compounds can exhibit similar biological properties (7).

The pharmacophore modeling method is applied to analyze the target's binding pocket or compounds known to interact with the target of interest. A list of available compounds is then made, and candidate compounds are compared with a scoring system and the pharmacophore model to find compounds similar to the pharmacophore model (8). Pharmacophore based drug repurposing yields results with higher accuracy than molecular docking and is considered computationally less demanding. However, only a very small fraction of the virtual results obtained as a result of pharmacophore modeling contain real bioactive compounds. Therefore, optimization and validation become even more important.

Quantitative QSAR methods use the relationship and interactions between the target protein and the ligand, and these interactions play key roles in analyzing the properties of drugs. QSAR models are based on the principle that molecules with similar structures show similar biological activity. It also uses statistical methods to associate drug-target interactions with different molecular properties. Sufficient data is needed to allow the extraction of necessary features to apply this approach. The main difference 
between the pharmacophore model and QSAR methods is that the pharmacophore model is based only on the basic properties of a ligand, while in QSAR methods, both the essential properties of the ligand and the properties related to the activity between the ligand and the target are taken into account (9).

In the reverse docking method, the library of clinically proven targets within the scope of repositioning drugs is screened for a single ligand in order to expand the indications of the compounds. Based on a specific scoring system, the result of this screening is taken as a list of goals. According to this list, the highest-scoring targets may be used for drug repurposing because the highest scoring targets have a higher potential to bind to the specific ligand (10).

In order to apply the reverse docking method within the scope of drug repurposing, information about the potential ligandbinding sites as well as the structural library of target proteins is required (11). In the absence of this information, various computer programs can be used to predict the ligand-binding sites, but the sensitivity of the results will be questionable (12). The ligand must be an approved drug or an experimental or research drug, and this information must be obtained from databases such as DrugBank, National Institutes of Health (NIH) Chemical Genomics Center Pharmaceutical Collection, and Chemical Database of Bioactive Molecules. Databases such as Potential Drug Target Database are available for reverse docking (13).

\section{Methods Based on Bioinformatics Data}

\section{Transcriptomic Based Drug Repositioning}

Rapid advances in genomics have allowed the acquisition of large-scale genomic and transcriptomic data both in healthy humans and animal tissue/cell samples and in a variety of diseases or disease models. Based on the transcriptomic data containing the list of genes whose expression level decreased or increased in biological samples obtained from healthy and sick individuals under different experimental conditions, whether drug therapy changes the expression profiles of the evaluated genes could be determined (14). This approach to using transcriptomic data available for drug repurposing has been used successfully in many cases and has given promising results. For example, Okada et al. (15) scanned gene loci that may be associated with rheumatoid arthritis and identified existing drugs associated with genes in this region. This development has revealed the potential of these drugs to be repositioned for rheumatoid arthritis (15).

\section{Genetic Variation Based Drug Repositioning}

Genome-wide association studies (GWAS) are a new approach that involves the rapid screening of all DNA sequences of many people to find genetic variations associated with a particular disease. Researchers use this data to identify genes associated with a particular disease trait and to investigate how these variations affect drug responses. GWAS can detect thousands of single nucleotide polymorphisms simultaneously, and this data source is used to make associations about complex diseases such as Alzheimer's disease and multiple sclerosis. GWAS can detect gene-disease relationships that are valuable within the scope of drug repurposing and can bring new indications to existing drugs (16). By combining existing data of 7,000 genes and 2,500 diseases, Nelson et al. (17) revealed 16,000 disease-gene relationships and 19,000 drug targets-disease relationships and showed that selecting genetic targets can double the success rates of clinical drug development programs.

\section{Literature Mining Based Drug Repositioning}

Today, information has spread to many different journals, databases, or scientific platforms, and the network is expanding day by day. Literature mining is used to identify and connect many seemingly unrelated indirect links and relationships of available scientific literature. It is possible to discover drugs and identify new drug indications by using all available and accessible literature with the help of computerized literaturebased approaches (18). In this method, based on a large scientific literature, the links between relevant data are analyzed to identify and describe the basic molecular mechanisms of a disease.

One of the sensitive points of literature-based drug discovery and repositioning is the selection of appropriate information sources. Information about abstracts, publications, gene and disease interactions, and protein-protein interactions in Pubmed, which is a very rich database in life sciences and biomedical fields, is frequently used in drug repurposing studies.

\section{Drug Repositioning Strategies and COVID Treatment}

Drug repositioning using the techniques reported above is possible with three different strategies as target-based, diseasebased, or drug-based (19). Drugs that have the potential to be reevaluated using these approaches in the treatment of COVID-19 are listed below.

\section{Target Based Approach}

In the target-based approach relationship between a drug molecule and protein interactions is examined. In this approach, defining the use of a drug in a new indication depends on a well-defined goal. In drug research and development studies for COVID-19 in line with the target-based approach, angiotensin-converting enzyme 2, Spike protein, Transmembrane Serine Protease 2 (TMPRSS2), severe acute respiratory syndrome coronavirus-2 (SARS-CoV-2) main protease (Mpro) also known as 3C-like protease (3-chymotrypsin-like protease or 3CLpro), papainlike protease (PLpro), ribonucleic acid (RNA)-bound RNA polymerase (RdRp), E protein, and Helicase were determined as target proteins. The cluster of differentiation 147 (CD147) receptor has also been identified as a therapeutic target $(20,21)$.

\section{Approaches Targeting the ACE2 Enzyme}

SARS-CoV-2 was shown to perform membrane fusion by attaching to ACE2 through the receptor binding site of spike proteins and thus can enter the human cell (22). A study used a library of antiviral compounds, including 2,924 molecules in the ZINC database and 78 commonly used antiviral drugs in the market, for target-based analysis. These libraries included 
those subjected to clinical trials for SARS-CoV-2, and whether the target was screened among the targets mediating the possible effects of these candidate drugs was investigated. As a result of this screening, 22 molecules used as drugs were also found to have ACE-2 enzyme inhibition potential. These were foscarnet, estradiol benzoate, thalidomide, troglitazone, cefamandol, losartan, benzylpenicilloyl G, ergotamine, methotrexate, cefmenoxim, carboprost, gadobenate dimeglumine, trandolapril, folinic acid, tranilast, meclizin, ziprasidon, dicumarol, riboflavine5-phosphate, silibinin, carmine, and cinnarizine (23).

\section{Approaches Targeting Spike Protein of the SARS-CoV-2 Virus}

REGN-3051 and REGN-3048 are monoclonal antibodies targeting the spike protein of the MERS-CoV virus. Based on the antigenic site similarities between MERS-CoV and SARS$\mathrm{CoV}-2$, it is thought that these monoclonal antibodies may have the potential to target SARS-CoV-2. The phase 1 clinical study (NCT03301090) with these monoclonal antibodies has been completed.

In the study conducted by Wu et al. (23), 29 molecules targeting the spike protein were found as a result of target-based virtual ligand scanning. These are azlocillin, penicillin, liothyronine, gliclazide, telmisartan, cefsulodin, seliprolol, levodopa, sorafenib, posaconazole, itraconazole, iloprost, etofilin clofibrate, fenofibrate, sildenafile, vardenafil, dabigatran etexilate, pioglitazon, vitamin $C$ and $\beta$-carotene and rescinnamine (23).

In another study, 7,922 molecules from the NPC database were screened by targeting the SARS-CoV-2 Spike protein receptor binding site. According to this study, denopamine, bometolol, naminterol, rotigaptid, and benzquercin molecules were determined as potential ACE2 inhibitors (24).

\section{Approaches Targeting TMPRSS2}

SARS-CoV-2 uses TMPRSS2 to prepare spike (S) protein (25). Camostat, previously approved for the treatment of chronic pancreatitis and postoperative reflux esophagitis, has been shown to inhibit TMPRSS2 via serine protease inhibition. A study demonstrated that SARS-CoV and human coronavirus (NL63) infections were partially prevented by inhibiting TMPRSS2 in HeLa cells (26). Therefore, the effectiveness of Camostat against the SARS-CoV-2 virus is being investigated. In an in vitro study, Camostat has been shown to significantly reduce the infection of Calu-3 lung cells by SARS-CoV-2 (25).

In the study conducted by Wu et al. (23), 26 drug molecules were found as potential TMPRSS2 inhibitors as a result of target-based virtual ligand scanning. These were abacavir, fulvestrant, pivampicillin, metacillin, montelukast, cefoperazone, ceftazidime, fludarabin, azlocillin, ceftizoxime, ceforanid, ethacrynic acid, cefotaxime, methotrexate, rosoxacin, alitretinoin, azacitidine, telmisartan, olmesartan, levofloxacin, clindamycin, trimethobenzamide, acrivastine, glibenclamide, and tetrahydrofolic acid.

Elmezayen et al. (27) also analyzed 4,500 molecules obtained from ChEMBL, DrugBank, and Selleckchem databases and 30,000 molecules from ZINC15 database by target- based scanning in another study. As a result of this analysis, 4 molecules were determined as potential TMPRSS2 inhibitors. Of these molecules, Rubitecan is a topoisomerase inhibitor, and Loprazolam is an anxiolytic. The other two molecules are ZINC000015988935 and ZINC000103558522 that have the capacity to be drugs (drug-like compounds) in the ZINC15 database (27).

\section{Approaches Targeting the SARS-CoV-2 Master Protease}

SARS-CoV-2 Mpro also known as 3C-like protease (3-chymotrypsin-like protease or 3CLpro) is involved in activating viral proteins produced in the host cell. It performs this activation by cutting unfolded viral proteins (28).

In the study conducted by Wu et al. (23), 27 drugs were identified as potential 3CLpro inhibitors as a result of targeted virtual ligand scanning in the ZINC database. These were lymecycline, chlorhexidine, alfuzosin, cilastatin, famotidine, almitrin, progabid, nepafenac, carvedilol, amprenavir, tigecycline, demeclocycline, montelukast, cefpyramide, pheneticillin, candoxatril, nicardipine, estradiol valerate, pioglitazone, conivaptan, telmisartan, doxycycline and oxytetracycline, carminic acid, mimocin, flavine mononucleotide and lutein molecules. (23). Bagherzadeh et al. (29) screened 160 antiviral molecules from the DrugBank database against the SARS-CoV-2 master protease target. As a result of this screening, 21 molecules were found as potential SARS-CoV-2 major protease inhibitors. These were antiviral drug molecules like adafosbuvir, amprenavir, asunaprevir, atazanavir, boseprevir, darunavir, galidesivir, indinavir, ritonavir, sofosbuvir, sorivudine, telaprevir, tenofoviralafenamide, inarigivir, merimepodib, nelfinavir, remdesivir, taribavirin, and molecules whose phase 2 studies were completed like L-756423 and TAS-106. This study also screened PapaineLike Protease target. Thus, seven molecules were found that are potential dual inhibitors for both SARS-CoV-2 master protease and papain-like protease. Among them, inarigivir, merimepodib, nelfinavir, remdesivir, taribavirin, and valganciclovir are the molecules used as drugs. TAS-106 molecule, whose phase 2 study has been completed, was also included in the list (29).

Durdagi et al. (24) found eight molecules as potential SARSCoV-2 main protease inhibitors. These were rotigaptid, telinavir, ritonavir, terlakiren, cefotiam, cefpyramid pimelautide, and pinokalant (24).

In another study, Elmezayen et al. (27) screened based on the SARS-CoV-2 Main Protease target. As a result of this screening, four molecules were found as potential SARS-CoV-2 Main Protease inhibitors. These were penicillin antibiotic talampicillin and antipsychotic lurasidone. The other two molecules in the list were ZINC000000702323 and ZINC000012481889 molecules, which have the capacity to be drugs (27).

\section{Approaches Targeting Papain-like Protease}

Papain-like proteinase (PLpro) is responsible for the cleavage of the N-terminal of the Replicase poly-protein. With this cleavage, Nsp1, Nsp2, and Nsp3, which are responsible for regulating 
virus replication, are released. It has also been confirmed that PLpro is responsible for antagonizing the innate immunity of the host (30).

As a result of target-based virtual ligand scanning Wu et al. (23) found that 29 drugs could be potent papain-like protease inhibitors. These were ribavirin, valganciclovir, thymidine, oxprenol, doxycycline, acetophenazine, lopromid, riboflavin, reproterol, chloramphenicol, chlorphenecin carbamate, levodropropizine, sefamandol, floxuridine, tigecycline, pemetrexed, ademethyldilazine, masoproxol, isotretinoin, dantrolene, nicardipine, sildenafile sulphasalazine, silibin, glutathione, hesperetin; L (+) - ascorbic acid, aspartame and finally $2.2^{\prime}$-cyclotidine molecules (23).

Bagherzadeh et al. (29) also found 21 potential inhibitor molecules in their screening study for a papain-like protease target. These were drugs such as penciclovir, lopinavir, maribavir, ribavirin, vidarabin and zanamivir, inarigivir, merimepodib, elsulfavirin, faldaprevir, famciclovir, nelfinavir, remdesivir, taribavirin, valganciclovir, ascorbic acid, GS-6620, cytarabine drugs 2-phase deoxyglucose and TAS-106 molecule whose phase-2 study has been completed. In addition, the 5-guanylmethylene bisphosphonate molecule used in experimental studies is also on the list (29).

\section{Approaches Targeting RNA Dependent Rna Polymerase}

Nsp12, a protein conserved in the coronavirus, is an (RNA)dependent RNA polymerase (RdRp) and is the vital enzyme of the coronavirus replication/transcription complex (31).

In the study conducted by Wu et al. (23), 20 molecules were identified as potential RdRp inhibitors among drug molecules as a result of target-based virtual ligand screening. These wee valganciclovir, chlorhexidine, ceftibuten, fenoterol, fludarabine, itraconazole, cefuroxime, atovaquone, chromoline, pancuronium bromide, cortisone, tibolone, novobiosin, idarubicin, bromocriptine, diphenoxylate, benzylpenisylloil G polylysine, dabigatran etexilat, chenodeoxycholic acid, and syllibinin (23).

\section{Approaches Targeting the E Protein}

E protein (E-channel) has important biological functions for the structural integrity of coronavirus and host virulence. $\mathrm{E}$ (Envelope) protein forms the viral envelope. Wu et al. (23) identified 23 potential inhibitor molecules as a result of virtual ligand screening based on the E protein target. These were ritonavir, amprenavir, atazanavir, valrubicin, montelucast, candesartan, sofalcon, ceftizoxime, xipamide, piperacillin, cefpyramid, demecarium bromide, sulfasalazine, quinapril, chlorhexidine, benzylpenicilloyl G polylysine, ergotamine, flusemethanethane, flushedrine, hyperforin and lutein molecules (23).

\section{Approaches Targeting the Helicase Protein}

Helicase (Nsp13) is a multifunctional protein. The SARS-Nsp13 sequence has been reported to be a necessary component for coronavirus replication. Therefore, it has been identified as a target for antiviral drug discovery.
In their target-based virtual ligand screening studies, Wu et al. (23) found that 27 drug molecules could be potential inhibitors of the Helicase enzyme. These were carbenicillin, olsalazine, imipenem, vidarabin monophosphate, gadobenate dimeglumine, benzylpenicillin, etacrinic acid, dienestrol, limexiline, tolmetin, folinic acid, 5-aminolevulinic acid, acetylcysteine, eprosartan, cefsulodin, saquinol, methotrexin, vitrexavine, dabigatran, antrafenine, ceftazidime, canrenoic acid, glutathione, and gadoteridol (23).

\section{Approaches Targeting CD147 Receptor}

The spike protein of the SARS-CoV-2 virus binds to the CD147 receptor, a receptor on target cells, thus infecting the target cell. For this reason, the CD147 receptor has been determined as a target in drug research and development studies for SARS-CoV-2 virus. Meplazumab, an anti-CD147 monoclonal antibody, has been shown to be effective in the treatment of COVID-19 (20).

\section{Disease-based Approach}

In the disease-based approach, the purpose is to bring new indications to drugs by examining the characteristics and common profiles of different diseases. A drug may be indicated for use in another disease with similar pathology to the pathology of the disease for which that drug is indicated. In this context, the disease-based approach is based on the common molecular pathology similarity between diseases or on related diseases (19).

\section{Antiviral Drugs}

Within the scope of the disease-based drug repositioning approach, taking into account that COVID-19 is based on an RNA virus, antiviral drugs have been used. Antiviral therapy is known to be beneficial when initiated earlier in the course of the disease in both influenza and SARS (32). In line with information obtained from SARS and Middle East Respirotary Syndrome (MERS) outbreaks, repositioning existing antiviral drugs to combat the current coronavirus epidemic is considered one of the fastest ways to achieve results. Despite the urgent need to find an effective antiviral treatment for COVID-19 through randomized controlled trials, some agents are used worldwide, based on in vitro or in vivo evidence or observational studies. However, there is a need for precise clinical research data on drugs considered to be used for safe and effective treatment of the disease.

\section{Remdesivir}

Remdesivir is a broad-spectrum antiviral agent developed by Gilead Sciences for the treatment of Ebola RNA virus infection in 2017. Animal studies have shown that remdesivir can effectively reduce the viral load in the lung tissue of MERS-CoV infected mice, improve lung function and alleviate pathological damage to lung tissue (33). Wang et al. (22) also found that remdesivir strongly blocks SARS-CoV-2 infection at low micromolar concentrations (34). In the preliminary data of a clinical study conducted with 1063 patients from 10 different countries, remdesivir was found to be superior to placebo in shortening the recovery time and in the treatment of lower respiratory tract infection 
in adults hospitalized with COVID-19 (NCT04280705) (35). Many clinical trials for remdesivir are ongoing. FDA, approved (Emergency Use Authorization) remdesivir, whose effectiveness in COVID-19 treatment has not been absolutely demonstrated, only as a research drug, and as an emergency drug for suspected, laboratory-confirmed or severe COVID-19 treatment as Emergency Use Authorization. The European Medicines Agency Human Medicinal Products Committee reviewed data on the use of remdesivir for COVID-19 treatment on May 15, 2020, and put forward recommendations on how to use remdesivir.

\section{Favipiravir}

Favipiravir is a new type of RNA-dependent RNA polymerase (RdRp) inhibitor drug, approved in 2014 for use in the treatment of pandemic influenza virus infections in Japan (36). Favipiravir, which is activated after being taken into the cell and is accepted as a substrate by viral RNA polymerases, is thought to inhibit RNA polymerase activity. China approved the effectiveness of favipiravir in the treatment of COVID on March 17, 2020. Phase 3 studies on favipiravir in Japan were initiated on March 31, 2020, and a Phase 2 study in America was initiated on April 9, 2020 (NCT04349241, NCT04402203, NCT04376814, NCT04310228). Favipiravir is approved for use in the treatment of COVID-19.

\section{Lopinavir + Ritonavir Combination}

Lopinavir is a highly specific protease inhibitor for HIV-1 and HIV-2; ritonavir increases the plasma concentration of lopinavir through inhibition of cytochrome P450 (37). Ritonavir + lopinavir combination has been shown to be beneficial in patients with SARS infection, and a randomized controlled clinical trial was initiated in 2018 to evaluate the effect in patients with MERS-CoV infection in combination with IFN (MIRACLE trial; NCT02845843) (38). In a randomized, controlled, openlabel study, 199 inpatients with severe SARS-CoV-2 infection were randomized to receive lopinavir + ritonavir and standard care for 14 days or only standard care. According to the results of the study, there was no significant difference between combination therapy and standard therapy (39). However, in another study, patients in the group in which interferon was added to lopinavir $400 \mathrm{mg}+$ ritonavir $100 \mathrm{mg}$ every 12 hours for 14 days, and alternately 3 doses $\times 8$ million IU interferon beta- $1 \mathrm{~b}$ or ribavirin $100 \mathrm{mg}$ were shown to be more effective at improving symptoms, reducing viral load and shortening the length of hospital stay than the group receiving the combination of lopinavir $400 \mathrm{mg}$ and ritonavir $100 \mathrm{mg}$ (40).

\section{Umifenovir}

Umifenovir is a membrane fusion inhibitor that targets viral entry. Umifenovir has demonstrated antiviral activity in vitro on widely spread virus strains such as Ebola virus, human herpesvirus 8 , hepatitis $C$ virus (41). In vitro activity of umifenovir against SARS-CoV-1 and SARS-CoV-2 were reported. (42). There are randomized clinical trials in China investigating the efficacy and safety of umifenovir against COVID-19 (NCT04252885, NCT04260594).

\section{Bemcentinib}

Bemcentinib is an AXL kinase inhibitor, previously studied in cancer patients and has been shown to be safe and well-tolerated. It has also been reported to exhibit potent antiviral activity in preclinical models against a variety of enveloped viruses, including Ebola and Zika virus. Recent data has expanded this to include SARS-CoV-2. A multi-center Phase II clinical study is being followed in England to examine its effectiveness in the treatment of hospitalized patients with COVID-19.

\section{EIDD-2801}

EIDD-2801 is a powerful ribonucleoside analog that inhibits the replication of RNA viruses, including SARS-CoV-2. In animal studies of two different $\mathrm{CoV}$ (SARS-CoV-1 and MERS), EIDD-2801 has been shown to improve respiratory function, reduce body weight loss, and reduce the amount of virus in the lung (43). Permission has been obtained from the FDA to begin clinical work by licensing the EIDD-2801 in collaboration with Ridgeback Biotherapeutics and Merck. It has 3 clinical trials (NCT04392219, NCT04405570, NCT04405739).

\section{Anti-inflammatory Drugs and Anti-cytokine Treatments}

An increase in immune reactions called "cytokine storm" and excessive production of cytokines is blamed for the rapid progression and exacerbation of COVID-19 infection. In critical COVID-19 patients, there is an excessive increase in the levels of inflammatory markers $\mathrm{C}$-reactive protein and inflammatory cytokines [such as interleukin (IL)-6, TNF-a, IL-1, IL-8] in parallel with the decrease in lymphocyte count (44). In this context, the use of glucocorticoids, nonsteroidal anti-inflammatory drugs, chloroquine/hydroxychloroquine, immunosuppressive drugs, immunomodulatory drugs, and inflammatory cytokine antagonists has been considered. These include monoclonal antibodies that bind to IL-6R and antagonize its effect, TNF-alpha inhibitors, IL-1 antagonists, and janus kinase inhibitors.

\section{Corticosteroids}

In a retrospective study of 200 patients with acute respiratory distress syndrome (ARDS), a lower mortality rate was seen in patients receiving methylprednisolone (45). The number of clinical studies investigating the effects of different formulations and dosages on the use of corticosteroid drugs in COVID-19 pneumonia is constantly increasing. Following studies can be given as examples of studies investigating the effects of methylprednisolone (NCT04263402, NCT04323592, NCT04343729, NCT04273321, NCT04263402, NCT04323592, NCT04343729, NCT04273321, NCT04263402, NCT04323592, NCT04343729, NCT04273321, NCT0424354591), dexamethasone (NCT04243, NCT04331470) or dexamethasone with Siltuximab or Tacrolimus like other anti-inflammatory combination treatments (respectively NCT04329650, NCT04341038). The effect of thalidomide + low dose glucocorticoid combination on patients with severe COVID-19 is evaluated in terms of clinical efficacy (NCT04273529). 


\section{Ciclesonide}

The antiviral and anti-inflammatory effects of ciclesonide, an approved corticosteroid effective in controlling chronic inflammation of the respiratory tract, is expected to be effective in the treatment of lung damage seen in severe coronavirus infections. There is a preliminary publication showing in vitro experiments that ciclesonide inhibits SARS-CoV-2 replication via viral nsp15 inhibition (46). Clinical trials have been initiated for the use of inhaled ciclesonide in COVID-19 (NCT04381364).

\section{Interleukin-6 Antagonists}

Tocilizumab is marketed as Actemra for the treatment of rheumatoid arthritis and other inflammatory conditions. In a small cohort (21 patients) retrospective study conducted in China, IL-6 receptor (IL-6R) monoclonal antibody (mAb) Tocilizumab (TCZ) developed by Genentech was able to rapidly improve clinical outcomes, normalize the fever in patients within one day, and reduce the oxygen need of $75 \%$ of the patients within five days in severe COVID-19 patients (47). There are many clinical trials (NCT04335071, NCT04306705, NCT04332094, NCT04332913) on tocilizumab, and the Chinese National Health Commission has approved its use against lung damage in patients with severe COVID-19.

Similarly, the therapeutic potential of Sarilumab, another IL-6 antagonist monoclonal antibody marketed as Kevzara for the treatment of rheumatoid arthritis, for (ARDS) in COVID-19 patients is being investigated (NCT04359901, NCT04386239, NCT04357808, NCT04324073).

\section{Interferon Antagonists}

It is thought that Emapalumab, an FDA-approved anti-IFN- $\gamma$ monoclonal antibody for hemophagocytic lymphohistiocytosis, can suppress the increased cytokine production during COVID-19 infection. There is 1 clinical study investigating the efficacy and safety of its combined use with Anakinra in the treatment of COVID-19 (NCT04324021).

\section{JAK1/2 Inhibitors}

Barisitinib, a JAK1/2 inhibitor, is a licensed anti-inflammatory drug for the treatment of rheumatoid arthritis (RA). It is estimated that barisitinib may show antiviral activity by inhibiting AAK1, an important regulator of viral endocytosis (48), and there are clinical studies related to this (NCT04320277).

Ruxolitinib (Jakafi) was first approved by the FDA for the treatment of myelofibrosis, then polycythemia vera, and acute graft versus host disease in 2019. It was thought that this drug could be effective in the cytokine storm caused by COVID-19 infection by inhibiting the JAK/STAT pathway. For this reason, a clinical study has been initiated for the use of Ruxolitinib in the treatment of COVID-19 (NCT04414098).

\section{S1P1 Inhibitors}

Fingolimod is an approved S1P1 inhibitor with immunomodulatory and immunosuppressant effects. In influenza virus infection models in mice, this drug has been shown to reduce mortality and morbidity by reducing the release of proinflammatory cytokines (49). A clinical trial continues for the use of Fingolimod in COVID-19 (NCT04280588).

\section{Colchicine}

Colchicine is an immune system modulator that has long been used in the treatment of gout. Clinical trials of colchicine have been initiated in high-risk COVID-19 patients due to its potential to reduce cytokine release and inflammation and prevent complications (NCT04360980, NCT04375202, NCT04350320).

\section{Leronlimab}

ARDS seen in COVID-19 is thought to be caused by cytokine storm due to the accumulation of neutrophils in the pulmonary circulation and alveolar spaces. Leronlimab (PRO 140) can alleviate the cytokine storm seen in COVID-19 by preventing the migration of macrophages and the release of proinflammatory cytokines in the lungs. In this context, treatment with Leronlimab (CCR5 antagonist) has been shown to improve severely depleted CD8 T-lymphocyte percentages, normalize CD4/CD8 ratios, and decrease IL-6 levels in critical or terminal COVID-19 patients (50). Apart from this, there are two more clinical studies, the results of which have not yet been announced regarding the use of leronlimab in COVID-19 (NCT04347239, NCT04343651).

\section{Medications Recommended for Lung Symptoms}

Vascular endothelial growth factor (VEGF), which has been reported to have increased levels in acute lung injury (ALI) and (ARDS), is considered a potential therapeutic target in COVID-19, as it is known to cause increased vascular permeability and pulmonary edema (51).

Bevacizumab, marketed under the name Avastin for certain types of cancer, is a monoclonal antibody that inhibits VEGF. Bevacizumab was predicted to reduce pulmonary edema and mortality in ALI and ARDS treatment, and a clinical study was initiated in patients with severe COVID-19 pneumonia (NCT04275414, NCT04305106).

\section{Drug Based Approach}

The drug-based approach is based on the similarities in chemical structures of a drug not used in the target indication with the drugs used in that indication. In this approach, a new target is defined that links the drug to a new indication. The drug-based approach is based on chemical structure similarity, pharmacological action similarity, and molecular coupling between drugs (19).

\section{Chloroquine-hydroxychloroquine}

Chloroquine is a drug used in the treatment of malaria accompanied by high fever (52). Chloroquine may block SARS$\mathrm{CoV}$ virus entry by altering the ACE-2 receptor and spike protein glycosylation (53). In 2003, chloroquine was found to be effective against the SARS-CoV virus that caused the SARS epidemic and was used in treatment (53). Similarly, chloroquine has been shown to effectively inhibit SARS-CoV-2 in vitro (34). 
The effectiveness of hydroxychloroquine, a less toxic derivative of chloroquine with fewer side-effects, previously used in the treatment of patients with malaria, lupus, and arthritis, against the COVID-19 epidemic was also investigated (54). A study demonstrated that hydroxychloroquine is weakly alkaline and prevents endosomal acidification by increasing endosomal $\mathrm{pH}$, thus preventing virus-target cell membrane fusion (52). Hydroxychloroquine also has anti-inflammatory and immunomodulatory effects. Hydroxychloroquine has been shown to be effective in vitro in SARS-CoV-2 infection (54). Following the demonstration of in vitro activity of both chloroquine and hydroxychloroquine against SARS-CoV-2, many clinical studies have been initiated in terms of its potential for use in the treatment of COVID-19 $(34,54)$. On day six, after the inclusion of azithromycin and hydroxychloroquine combined therapy, virological improvement was observed in $100 \%$ of patients treated with the combination of hydroxychloroquine and azithromycin $57.1 \%$ in patients treated with hydroxychloroquine alone and $12.5 \%$ in the control group) (55). However, there are conflicting reports of chloroquine and hydroxychloroquine in small randomized trials and in some case reports. An article published in The Lancet magazine on May 22 demonstrated that the use of chloroquine or hydroxychloroquine in the treatment of COVID-19 increased mortality rates and caused heart rhythm disturbance. Subsequently, the article was withdrawn when serious scientific problems were revealed in the data of the study (56).

Despite all this, due to the rapid spread of COVID-19 and the increase in deaths, some countries have included chloroquine/ hydroxychloroquine in their treatment protocols by evaluating the preliminary data of ongoing studies. In Turkey COVID-19 Treatment Protocol, hydroxychloroquine is recommended in all categories of COVID-19 patients, from asymptomatic to critically ill category, if the physician deems appropriate (57). Hydroxychloroquine is included in the treatment protocol for mild/moderate and critical COVID-19 patients with risk factors in Italy, the Netherlands, and Belgium (58). (NIH) COVID-19 Treatment Guidelines recommend the use of highdose chloroquine $(600 \mathrm{mg}$ twice daily for ten days) to treat COVID-19 (59).

French soldiers used chloroquine as a prophylactic $100 \mathrm{mg}$ per day for many years while working in areas with a high incidence of malaria. There is not enough data for the prophylactic use of chloroquine/hydroxychloroquine in COVID-19. In some treatment protocols, hydroxychloroquine can be used prophylactically to prevent asymptomatic patients from spreading the virus rapidly and protecting healthcare workers. In this context, a randomized, double-blind clinical study has been initiated, including 40,000 healthcare workers from Asia, Europe, and Africa (NCT04303507). Turkey COVID-19 Treatment Protocol stated that hydroxychloroquine can be used as $2 \times 200 \mathrm{mg}$ for 5 days in asymptomatic patients depending on the physician's choice (57).

\section{Ivermectin}

After the discovery that antimalarial chloroquine and hydroxychloroquine are effective in COVID-19, studies on another antimalarial drug, İvermectin, have accelerated. An in vitro study conducted at Monash University in Australia demonstrated the effectiveness of Ivermectin, an antiparasitic drug, against the SARS-CoV-2 virus. However, in order for the drug to be used in patients diagnosed with COVID-19, it is necessary to verify the effectiveness of the drug in patients with COVID-19. Therefore, more data are needed, and more clinical studies need to be concluded (60).

\section{Azithromycin}

Azithromycin is a broad-spectrum macrolide antibiotic used in the treatment of respiratory, enteric, and genitourinary system infections. In a study conducted in France, a combination of hydroxychloroquine and azithromycin was administered to 20 patients diagnosed with COVID-19 to prevent bacterial superinfection and to provide a significant reduction in viral load. According to the study, all patients recovered virologically within 6 days following treatment (55). On May 14, 2020, NIH started studies on the use of hydroxychloroquine and azithromycin in COVID-19. According to the Ministry of Health COVID-19 treatment protocol, combination therapy with azithromycin and hydroxychloroquine is recommended for patients with uncomplicated mild pneumonia and COVID-19 with severe pneumonia (57).

\section{Conclusion and Recommendations}

Drug repositioning methods save both time and cost compared to traditional drug development methods. Drug repositioning has a life-saving importance for human health by skipping some of the clinical phase tests in pandemic situations such as COVID-19 and allowing rapid access to the drug. Recent efforts to develop a treatment for COVID-19 employed drug repositioning rather than drug and target-based strategies. On the other hand, some drugs that were investigated using the disease-based approach strategy did not make a significant difference in clinical studies. Therefore, although in vitro data and in silico approaches are promising for rapid drug discovery in the treatment of COVID-19, the necessity of waiting for the results of clinical trials for approval of indications by drug authorities has become clearer during the COVID-19 pandemic process.

\section{Authorship Contributions}

Concept: G.Y.A., Design: G.Y.A., Literature Search: M.S., E.N.Ö., Writing: M.S., E.N.Ö., G.Y.A.

Conflict of Interest: No conflict of interest was declared by the authors.

Financial Disclosure: The authors declared that this study received no financial support.

\section{References}

1. Park SE. Epidemiology, virology, and clinical features of severe acute respiratory syndrome -coronavirus-2 (SARS-CoV-2; Coronavirus Disease-19). Clin Exp Pediatr. 2020;63:119-24. 
2. Nosengo N. Can you teach old drugs new tricks? Nature 2016;534:314-6.

3. Jourdan JP, Bureau R, Rochais C, Dallemagne P. Drug repositioning: a brief overview. J Pharm Pharmacol. 2020;72:1145-51. doi: 10.1111/jphp.13273.

4. Oprea TI, Bauman JE, Bologa CG, Buranda T, Chigaev A, Edwards BS, et al. Drug repurposing from an academic perspective. Drug Discov Today Ther Strateg 2011;8:61-9.

5. Meng XY, Zhang HX, Mezei M, Cui M. Molecular docking: a powerful approach for structure-based drug discovery. Curr Comput Aided Drug Des 2011;7:146-57.

6. Dakshanamurthy S, Issa NT, Assefnia S, Seshasayee A, Peters OJ, Madhavan S, et al. Predicting new indications for approved drugs using a proteochemometric method. J Med Chem 2012;55:6832-48.

7. Dudley JT, Deshpande T, Butte AJ. Exploiting drug-disease relationships for computational drug repositioning. Brief Bioinform 2011;12:303-11.

8. Hodos RA, Kidd BA, Shameer K, Readhead BP, Dudley JT. In silico methods for drug repurposing and pharmacology. Wiley Interdiscip Rev Syst Biol Med 2016;8:186-210.

9. Sliwoski G, Kothiwale S, Meiler J, Lowe EW Jr. Computational methods in drug discovery. Pharmacol Rev 2014;66:334-95.

10. Kharkar PS, Warrier S, Gaud RS. Reverse docking: a powerful tool for drug repositioning and drug rescue. Future Med Chem 2014;6:33342.

11. Lee A, Lee K, Kim D. Using reverse docking for target identification and its applications for drug discovery. Expert Opin Drug Discov 2016;11:707-15.

12. Yuan Y, Pei J, Lai L. Binding site detection and druggability prediction of protein targets for structure-based drug design. Curr Pharm Des 2013;19:2326-33.

13. Gao Z, Li H, Zhang H, Liu X, Kang L, Luo X, et al. PDTD: a web-accessible protein database for drug target identification. BMC Bioinformatics 2008;9:104.

14. Hurle MR, Yang L, Xie Q, Rajpal DK, Sanseau P, Agarwal P. Computational drug repositioning: from data to therapeutics. Clin Pharmacol Ther 2013;93:335-41.

15. Okada Y, Wu D, Trynka G, Raj T, Terao C, Ikari K, et al. Genetics of rheumatoid arthritis contributes to biology and drug discovery. Nature 2014;506:376-81.

16. Nabirotchkin S, Peluffo AE, Rinaudo P, Yu J, Hajj R, Cohen D. Nextgeneration drug repurposing using human genetics and network biology. Curr Opin Pharmacol 2020;51:78-92.

17. Nelson MR, Tipney H, Painter JL, Shen J, Nicoletti P, Shen Y, et al. The support of human genetic evidence for approved drug indications. Nat Genet 2015;47:856-60.

18. Andronis C, Sharma A, Virvilis V, Deftereos S, Persidis A. Literature mining, ontologies and information visualization for drug repurposing. Brief Bioinform 2011;12:357-68.

19. Parisi D, Adasme MF, Sveshnikova A, Bolz SN, Moreau Y, Schroeder $\mathrm{M}$. Drug repositioning or target repositioning: A structural perspective of drug-target-indication relationship for available repurposed drugs. Comput Struct Biotechnol J 2020;18:1043-55.
20. Wang K, Chen W, Zhou Y-S, Lian J-Q, Zhang Z, Du P, et al. SARS$\mathrm{CoV}-2$ invades host cells via a novel route: CD147-spike protein. bioRxiv 2020:2020.03.14.988345.

21. Wu R, Wang L, Kuo HD, Shannar A, Peter R, Chou PJ, et al. An Update on Current Therapeutic Drugs Treating COVID-19. Curr Pharmacol Rep 2020:1-15.

22. Wang Q, Zhang Y, Wu L, Niu S, Song C, Zhang Z, et al. Structural and Functional Basis of SARS-CoV-2 Entry by Using Human ACE2. Cell 2020;181:894-904 e9.

23. Wu C, Liu Y, Yang Y, Zhang P, Zhong W, Wang Y, et al. Analysis of therapeutic targets for SARS-CoV-2 and discovery of potential drugs by computational methods. Acta Pharm Sin B 2020;10:766-88.

24. Durdagi S, Aksoydan B, Dogan B, Sahin K, Shahraki A, Birgülİyison N. Screening of Clinically Approved and Investigation Drugs as Potential Inhibitors of SARS-CoV-2 Main Protease and Spike Receptor-Binding Domain Bound with ACE2 COVID19 Target Proteins: A Virtual Drug Repurposing Study. ChemRvix 2020. doi:10.26434/chemrxiv.12032712.v2.

25. Hoffmann M, Kleine-Weber H, Schroeder S, Kruger N, Herrler T, Erichsen S, et al. SARS-CoV-2 Cell Entry Depends on ACE2 and TMPRSS2 and Is Blocked by a Clinically Proven Protease Inhibitor. Cell 2020;181:271-80 e8.

26. Kawase M, Shirato K, van der Hoek L, Taguchi F, Matsuyama S. Simultaneous treatment of human bronchial epithelial cells with serine and cysteine protease inhibitors prevents severe acute respiratory syndrome coronavirus entry. J Virol 2012;86:6537-45.

27. Elmezayen AD, Al-Obaidi A, Sahin AT, Yelekci K. Drug repurposing for coronavirus (COVID-19): in silico screening of known drugs against coronavirus 3CL hydrolase and protease enzymes. J Biomol Struct Dyn 2020:1-13.

28. Armstrong JF, Faccenda E, Harding SD, Pawson AJ, Southan C, Sharman JL, et al. The IUPHAR/BPS Guide to PHARMACOLOGY in 2020: extending immunopharmacology content and introducing the IUPHAR/MMV Guide to MALARIA PHARMACOLOGY. Nucleic Acids Res 2020;48:D1006-D21.

29. Bagherzadeh K, Daneshvarnejad K, Abbasinazari M, Azizian H. In silico repositioning for dual inhibitor discovery of sars-cov-2 (covid-19) 3c-like protease and papain-like peptidase. Preprints 2020. doi: 10.20944/preprints202004.0084.v1.

30. Harcourt BH, Jukneliene D, Kanjanahaluethai A, Bechill J, Severson KM, Smith CM, et al. Identification of severe acute respiratory syndrome coronavirus replicase products and characterization of papain-like protease activity. J Virol 2004;7813600-12.

31. Subissi L, Imbert I, Ferron F, Collet A, Coutard B, Decroly E, et al. SARS-CoV ORF1b-encoded nonstructural proteins 12-16: replicative enzymes as antiviral targets. Antiviral Res 2014;101:12230.

32. Simsek Yavuz S, Unal S. Antiviral treatment of COVID-19. Turk J Med Sci 2020;50:611-9.

33. Sheahan TP, Sims AC, Leist SR, Schäfer A, Won J, Brown AJ, et al. Comparative therapeutic efficacy of remdesivir and combination lopinavir, ritonavir, and interferon beta against MERS-CoV. Nat Commun 2020;11:222. 
34. Wang M, Cao R, Zhang L, Yang X, Liu J, Xu M, et al. Remdesivir and chloroquine effectively inhibit the recently emerged novel coronavirus (2019-nCoV) in vitro. Cell Res 2020;30:269-71.

35. Beigel JH, Tomashek KM, Dodd LE, Mehta AK, Zingman BS, Kalil AC, et al. Remdesivir for the treatment of Covid-19-preliminary report. N Eng J Med 2020;383:1813-26.

36. Nagata T, Lefor AK, Hasegawa M, Ishii M. Favipiravir: a new medication for the ebola virus disease pandemic. Disaster Med Public Health Prep2014;9:79-81.

37. Soliman EZ, Lundgren JD, Roediger MP, Duprez DA, Temesgen Z, Bickel M, et al. Boosted protease inhibitors and the electrocardiographic measures of QT and PR durations. AIDS 2011;25:367-77.

38. Scavone C, Brusco S, Bertini M, Sportiello L, Rafaniello C, Zoccoli A, et al. Current pharmacological treatments for COVID-19: What's next? British Journal of Pharmacology. 2020. doi: 10.1111/ bph. 15072 .

39. Cao B, Wang Y, Wen D, Liu W, Wang J, Fan G, et al. A Trial of Lopinavir-Ritonavir in Adults Hospitalized with Severe Covid-19. N Eng J Med 2020;382:1787-99.

40. Hung IF-N, Lung K-C, Tso EY-K, Liu R, Chung TW-H, Chu M-Y, et al. Triple combination of interferon beta-1b, lopinavir-ritonavir, and ribavirin in the treatment of patients admitted to hospital with COVID-19: an open-label, randomised, phase 2 trial. Lancet 2020;395:1695-704.

41. Pécheur E-I, Borisevich V, Halfmann P, Morrey JD, Smee DF, Prichard M, et al. The Synthetic Antiviral Drug Arbidol Inhibits Globally Prevalent Pathogenic Viruses. J Virol 2016;90:3086.

42. Blaising J, Polyak SJ, Pecheur EI. Arbidol as a broad-spectrum antiviral: an update. Antiviral Res 2014;107:84-94.

43. Sheahan TP, Sims AC, Zhou S, Graham RL, Pruijssers AJ, Agostini $\mathrm{ML}$, et al. An orally bioavailable broad-spectrum antiviral inhibits SARS-CoV-2 in human airway epithelial cell cultures and multiple coronaviruses in mice. Sci Transl Med 2020;12:eabb5883.

44. Barnes BJ, Adrover JM, Baxter-Stoltzfus A, Borczuk A, Cools-Lartigue J, Crawford JM, et al. Targeting potential drivers of COVID-19: Neutrophil extracellular traps. J Exp Med 2020;217:e20200652.

45. Wu C, Chen X, Cai Y, Xia J, Zhou X, Xu S, et al. Risk Factors Associated With Acute Respiratory Distress Syndrome and Death in Patients With Coronavirus Disease 2019 Pneumonia in Wuhan, China. JAMA Intern Med 2020;180:934-43.

46. Matsuyama S, Kawase M, Nao N, Shirato K, Ujike M, Kamitani W, et al. The inhaled corticosteroid ciclesonide blocks coronavirus RNA replication by targeting viral NSP15. bioRxiv 2020:2020.03.11.987016.

47. Xu X, Han M, Li T, Sun W, Wang D, Fu B, et al. Effective treatment of severe COVID-19 patients with tocilizumab. Proc Natl Acad Sci U S A 2020;117:10970.
48. Richardson P, Griffin I, Tucker C, Smith D, Oechsle O, Phelan A, et al. Baricitinib as potential treatment for 2019-nCoV acute respiratory disease. Lancet (London, England). 2020;395:e30-e1.

49. Walsh KB, Teijaro JR, Wilker PR, Jatzek A, Fremgen DM, Das SC, et al. Suppression of cytokine storm with a sphingosine analog provides protection against pathogenic influenza virus. Proc Natl Acad Sci U S A. 2011;108:12018-23.

50. Pattterson B, Seetthamraju H, Dhody K, Corley M, Kazempour $\mathrm{K}$, Lalezari J, et al. Disruption of the CCL5/RANTES-CCR5 Pathway Restores Immune Homeostasis and Reduces Plasma Viral Load in Critical COVID-19. Research Square 2020.doi: 10.1101/2020.05.02.20084673.

51. Barratt S, Medford AR, Millar AB. Vascular endothelial growth factor in acute lung injury and acute respiratory distress syndrome. Respiration 2014;87:329-42.

52. Wu R, Wang L, Kuo H-CD, Shannar A, Peter R, Chou PJ, et al. An Update on Current Therapeutic Drugs Treating COVID-19. Curr Pharmacol Rep 2020;6:56-70.

53. Savarino A, Di Trani L, Donatelli I, Cauda R, Cassone A. New insights into the antiviral effects of chloroquine. Lancet Infect Dis 2006;6:67-9.

54. Liu J, Cao R, Xu M, Wang X, Zhang $\mathrm{H}$, $\mathrm{Hu} \mathrm{H}$, et al. Hydroxychloroquine, a less toxic derivative of chloroquine, is effective in inhibiting SARS-CoV-2 infection in vitro. Cell Discov 2020;6:16.

55. Gautret P, Lagier J-C, Parola P, Hoang VT, Meddeb L, Mailhe $\mathrm{M}$, et al. Hydroxychloroquine and azithromycin as a treatment of COVID-19: results of an open-label non-randomized clinical trial. Int J Antimicrob Agents 2020:105949.

56. Mehra MR, Desai SS, Ruschitzka F, Patel AN. RETRACTED: Hydroxychloroquine or chloroquine with or without a macrolide for treatment of COVID-19: a multinational registry analysis. Lancet 2020. doi:10.1016/S0140-6736(20)31180-6.

57. T.C. Sağlık Bakanlığı, Erişkin Hasta Yönetimi ve Tedavisi Rehberi. Last Accessed Date: 15.06.2020. Avaliable from: https://covid19bilgi. saglik.gov.tr/depo/tedavi/COVID19 EriskinHastaTedavisi.pdf.

58. Kamps BS, Hoffmann C. The new mini-textbook by Kamps \& Hoffmann. 2nd ed. Germany: Steinhauser Verlag; 2020:115.

59. COVID-19 Treatment Guidelines Panel. Coronavirus Disease 2019 (COVID-19) Treatment Guidelines. National Institutes of Health. Last Accessed Date:16.06.2020. Available from: https://www. covid19treatmentguidelines.nih.gov/.

60. Caly L, Druce JD, Catton MG, Jans DA, Wagstaff KM. The FDAapproved drug ivermectin inhibits the replication of SARS-CoV-2 in vitro. Antiviral Res 2020;178:104787. 